\title{
An Evaluation of a Major Airline Flight Internship Program: Participant's Perceptions of Curricular Preparation for, and Components of, the Internship
}

\author{
Jose R. Ruiz, David A. NewMyer, and D. Scott Worrells \\ Southern Illinois University Carbondale
}

\begin{abstract}
This article presents the results of a follow-up survey administered to 110 former university interns who served a semester-long flight operations internship at United Airlines. The intent of the survey was to obtain the participant's opinions concerning their academic preparation for the internship experience, as well as their overall assessment of the internship experience itself. Of the 78 respondents, $75.7 \%$ indicated that their university aviation curriculum had prepared them "very well" or "well" for the internship. Further, $80.7 \%$ of all respondents indicated that the semester-long internship had a "great impact" or "significant impact" in helping them achieve their career goals. Also, 96.2\% of all respondents said that they would recommend a United Airlines internship to students seeking an aviation career.
\end{abstract}

\section{INTRODUCTION}

In July 1987 Southern Illinois University at Carbondale (SIUC) and United Airlines signed a formal agreement to work together in establishing a flight operations internship partnership. Essentially, SIUC agreed to supply a well-prepared and preselected group of internship candidates. These candidates would then be evaluated during a one-to-two week "short internship" during which they would be formally interviewed for a semester-long "long internship". Since this agreement was signed, over 200 "short interns" and over 110 "long interns" (largely selected from the "short intern" group) have participated in this SIUC program.

As the university prepared for the celebration of the tenth anniversary of the signing of the internship agreement in 1997, SIUC faculty determined that this would be an excellent time to evaluate the flight operations internship program with United
Airlines. The demographic results of this survey (characteristics of the interns, then current employment, etc.) is the topic of an article published in JAAER entitled,

A Pioneering University-Airline Flight Internship Program: A Follow-Up Study of Intern Participants (1998). The purpose of this article is to present the results of survey data that address intern perceptions of curricular preparation for the United internship, and intern perceptions of United internship components.

\section{Methodology}

\section{Survey Participants}

Survey participants included all 110 SIUC aviation program students who participated in the United-SIUC "long internship" through August 1997. All 110 participants are also alumni of Southern Illinois University. 


\section{Survey Instrument Design}

The survey instrument was a mail-in questionnaire. The instrument was composed of six sections and designed to collect two types of information. First, it collected data related to the respondent's personal and professional characteristics. For example, types of Federal Aviation Administration (FAA) Aero-nautical Certificates possessed, flight time and level of education were among the type of data collected. Data concerning personal and professional characteristics of the respondents have already been reported by NewMyer, Ruiz, and Worrells (1998). The second type of data collected is attitudinal in nature. Using a Likert Scale, data concerning attitudes toward the internship experience, classes taught at SIUC, and other relevant topics were collected. The Likert Scale was used to allow respondents to indicate the extent to which they agreed or disagreed with a statement. The Likert Scale was selected because of its simplicity and ease of use. Attitudes were assessed along a 5-point scale. The points ranged from 1 to 5 . The scoring of statements was dependent upon the particular scale. For example, Section IV of the survey asks respondents to rate the helpfulness of aviation classes taught at SIUC. A high response (5) represents the highest degree of helpfulness, while a low response (1) represents the least helpfulness.

\section{Research Design}

The survey instrument was mailed to all 110 participants in the United-SIUC "long internship" program. The Department of Aviation Management and Flight in conjunction with the SIUC Alumni Association developed a comprehensive list of alumni addresses for graduates who participated in the United Airline "long internship". Three mailings were sent to these 110 alumni resulting in 78 responses, a return rate of $70.9 \%$. A $70.9 \%$ response rate represents an acceptable sample. Miller and Schumaker discuss questionnaire follow-ups and the impact they have on response rates: The initial mailing of the letter of transmittal, questionnaire, and stamped return-addressed envelope will usually result in a response rate of from forty to sixty percent - that is, forty to sixty percent of the sample will typically return the questionnaires. The first follow-up correspondence usually brings ten to twenty percent more returns, and a second followup will add another five to ten percent to the return rate. If researchers can obtain a total return of seventy percent or better, they are doing very well. In many studies the return rate is closer to fifty or sixty percent.

The survey questionnaire addressed four specific areas. The first three areas attempted to gauge respondent attitudes toward SIUC Aviation Flight-Aviation Manage-ment coursework and specific components of the short and long internship. The fourth area allowed the respondent to provide overall evaluative comments on the United-SIUC internship program:

1. What Aviation Flight-Aviation Management coursework was most helpful in preparing intern candidates for the flight operations internship?

2. How valuable was the "short internship" (specifically, components of the short internship) in developing the respondent's understanding of the airline industry and their development as an aviation professional?

3. How valuable was the "long internship" (again, components of the long internship) in developing the respondent's understanding of the airline industry and their development as an aviation professional? 
4. A series of overall evaluation questions addressing the value of the short and long internship to each respondent, how well the respondents believed they were prepared by SIUC for the internship and whether or not they would recommend the United Airlines Internship to others. Room was also left for essay responses from respond-ents who had additional questions.

\section{Definitions}

During the implementation of the United Airlines-Southern Illinois University Carbondale flight operations internship, two important learning opportunities were developed for SIUC students:

A. The Short Internship. This was initially a two week-long internship experience that took place at the United Airlines Flight Training Center in Denver, CO. This internship included a ground school on one of United's aircraft (usually the 767 since it was the only computerized, non-instructor ground school available in the late 1980's), presentations by key United personnel, tours, a group problem-solving activity and interviews for the long internship. In the early 1990's, the short internship was reduced to a one week experience with the ground school portion eliminated, but all of the other components mentioned above remained in the short internship. Ten SIUC students were allowed to participate in the short internship per semester. This was and still is an unpaid experience but United pays for the participants to fly to Denver and back from either St. Louis or Chicago. Students participating in the short internship were selected solely by United in the first years of the UA-
SIUC relationship, but in later years they were selected by SIUC alone. Selection criteria for the short internship are: a minimum overall grade point average of 2.75 on a 4.0 scale; Federal Aviation Administration Commercial Pilot Certificate with Instrument and Multiengine Ratings required and Certified Flight Instructor (Airplane) prefer-red; a relatively "clean" driving record (Driving Under the Influence or Driving While Intoxicated arrests were considered "knockout" factors); and the applicant must be an Aviation Management major at SIUC, having flown a minimum amount with the SIUC Aviation Flight program.

B. The Long Internship. The long internship refers to the semester-long experience that students attending the "short" internship (see above) interviewed for during the one or two week short internship. This internship lasts for a full semester rather than one or two weeks, thus the label "long" internship. Students attending the long internship were initially assigned to either the Denver Flight Training Center or to the United Airlines World Headquarters in Chicago. This was expanded to include any United Airline's Flight Operations domicile (pilot base). So far SIUC interns have served at Honolulu, Miami, Chicago, Denver, Los Angeles, Dulles (Washington, D.C.) and San Francisco. Interns are assigned projects appropriate to their work locations. During their internship they are flown to San Francisco for a tour of United's Maintenance Operations Center I. and also to Everett, Washington, for a tour of the Boeing Plant. This is an unpaid 
position; however, successful long interns graduating from SIUC are given "guaranteed processing privileges" (i.e., a guaranteed flight officer interview with United).

\section{Evaluation of SIUC Aviation Coursework}

Respondents were asked to report, “...what Aviation Flight/ Aviation Management course work (see Appendix) was most helpful to you in preparing for the United - SIUC internship?" Response categories were: $\mathrm{MH}=$ most helpful, $\mathrm{VH}=$ very helpful, $\mathrm{H}=$ helpful, $\mathrm{NVH}=$ not very helpful, $\mathrm{LH}=$ least helpful and N/A = not applicable. Based on the responses to these questions, it was determined that more than half of the 78 respondents took eleven SIUC aviation courses, or groups of courses (see Table 1).

Table 2 reports combined data for the "most helpful/very helpful" responses on each course and the "least helpful/not very helpful" responses on each course. Table 2 also reports these data as the percent of those taking each course so that the reader can see how the respondents reported their evaluation within each course subject area as well as how the overall totals compare across all courses.

As indicated in Table 3, three courses or groups of courses were ranked by more than half of all respondents as being either "Most Helpful" or "Very Helpful". These courses included: Flight Training at SIUC, AVM 373-Airline Management, and AVM 385/ATS 332-Air Transport Labor Relations. Among the 36 respondents reporting that they have been hired by United, Flight Training at SIUC was ranked first as the "Most Helpful" and "Very Helpful" course or group of courses with 29 of 36 respondents rating it in this fashion. Flight Training at SIUC was followed by AVM 385/ATS 332-Air Transport Labor Relations and AVM 373-Airline
Management tied for second with 23 respondents each, reflecting the "All Respondents" group result. When comparing the data in Table 2 and Table 3, it can be seen that, within the responses for each course, there is a slightly different ranking of courses between the two tables. The following ranking is arrived at by looking only at the total number of respondents who reported taking a specific course and then calculating the percentage of those who took only that course and ranked it as "Most Helpful/Very Helpful":

\section{Percent of Respondents taking}

Course Title the course who ranked it

1. AVM 373-Airline $82.1 \%$ Management

2. Flight Training $80.8 \%$ at SIUC

3. AMT 205-Cabin $\quad 65.2 \%$

Environment and Jet Transport Systems

4. AMT 405-Flight $\quad 64.7 \%$ Systems Management

5. AMT 385/ATS 332- $\quad 64.5 \%$

Air Transport Labor Relations

6. AVM 402/ATS 421- $\quad 58.8 \%$

Aviation Industry

Career Development

Using this method of ranking, all other courses were ranked $42.6 \%$ or lower (of those taking the course who rated it "Most Helpful/Very Helpful").

At the opposing end of the scale are those courses identified as "Least Helpful," or "Not Very Helpful" by all respondents. As noted in Table 4, AVM 370-Airport Planning was identified as the "Least Helpful" or "Not Very Helpful" course by 24 respondents, followed by AVM 372Airport Management, ATS 383-Data Interpretation and ATS 364-Work Center Management in a three-way tie with 19 such responses. Among those hired by United, AVM 370-Airport Planning and AVM 372Airport Management were tied as the "Least 
Helpful" or "Not Very Helpful" course with a score of 13 responses each.

\section{Short Internship Evaluation}

Since the second year of the United Airlines - SIUC Flight Operations Internship Program, a "short" (one to two week long) internship program has been offered by United Airlines to SIUC student participants. Respondents to the survey were asked to evaluate eleven items related to their short internship experience at United, including their overall short internship experience. They were provided a Likerttype scale with the following response categories for each item: Most Valuable, Very Valuable, Valuable, Somewhat Valuable, Not Valuable and Not Applicable. As shown in Table 5, six items were rated "Most Valuable or Very Valuable" by 42 $(53.8 \%)$ of all "short intern" evaluation respondents.

The following group of "Most Valuable/Very Valuable" short internship components varied slightly when ranked among the 36 respondents hired by United:

\section{Respondents Hired by United}

Interaction with

$72.2 \%$

United Personnel

Experiencing the

$69.4 \%$

Airline Work

Environment

Presentation by

United Personnel

Interview for the

"long internship"

$66.7 \%$

Short Internship

$63.9 \%$

Overall Experience

Simulator Time

$52.7 \%$
When the top group ranked by the 42 respondents not hired by United, there were a couple of major differences in responses. First, the "Short Internship Overall Experience" fell from a 66.7\% $\mathrm{MV} / \mathrm{VV}$ rating by those hired to a $45.2 \% \mathrm{MV} / \mathrm{VV}$ rating by those not hired. Also, the "767 (or other) Ground School" dropped from 44.4\% $\mathrm{MV} / \mathrm{VV}$ for those hired to $28.6 \% \mathrm{MV} / \mathrm{VV}$ for those not hired. The "Group Project with other Interns" was conversely ranked much higher by those not hired (at a 52.4\% MV/VV rating) than by those hired (38.9\%). Similarly, "Tours of TK" were rated fairly high at $50.0 \%$ by those "not hired" and $36.1 \%$ by those "hired".

Overall, only two items were given ten or more total "Somewhat Valuable/Not Valuable" responses by all respondents who evaluated the "short intern-ship":

Group Project

with other Interns

Tours of DEN/DIA

\section{Evaluation of the Long Internship}

In evaluating the "long" internship, respondents were again given a range of attitudinal questions with a Likert-type scale for response. The response options were the same as those provided for the short internship evaluation questions: Most Valuable (MV), Very Valuable (VV), Valuable (V), Somewhat Valuable (SV), Not Valuable (NV) and Not Applicable (N/A). Table 6 provides a combined consensus of the "Most Valuable/Very Valuable" responses and the "Not Valuable/Somewhat Valuable" responses.

The overall respondent group identified a very clear "Top 5" list of items in their responses, as all five items received over $80 \%$ respondent support: 
Component

1. Your internship experience

2. Observer Member of Crew (OMC) Privileges*

3. "Long" Internship Overall Experience*

$87.2 \%$

4. Interaction with United

Personnel (other than supervisor)

5. Your assigned work location at United

*Indicates a tie in ranking

Among those 36 respondents hired by United, this group of items stayed essentially the same, but in a slightly different order:
1. Your internship
$86.1 \%$ experience

2. Interaction with $80.6 \%$ United Personnel (other than supervisor)*

3. Long internship overall experience*

$80.6 \%$

4. Your assigned work location at United*
5. Observer Member $\quad 77.8 \%$ of Crew (OMC) Privileges*

*Indicates a tie in ranking

Among the 42 respondents not hired by United, OMC privileges jumped to the head of the list of items, but with the top five items again remaining the same items, while in yet another order of respondent preference:
1. OMC privileges
$95.2 \%$
2. "Long” Internship
$92.9 \%$ Overall Experience
3. Interaction with $\quad 90.5 \%$ United Personnel (other than supervisor)*
4. Your internship $\quad 90.5 \%$ experience*

5. Your assigned work $\quad 83.3 \%$ location at United

*Indicates a tie in ranking

Respondents were also asked via an open-ended type of question to rank the three "Most Valuable and Least Valuable" components of the "long" internship. Table 7 reports the combined "Most Valuable" responses, which indicate that "Interaction with United Personnel" received the most combined first, second, third "Most Valuable" responses, followed by OMC privileges. These two items received approximately twice as many responses as the three items tied in third place.

As far as internship items receiving the most responses for "Least Valuable" (see Table 8), leading the pack was a combined "Tours" (MOC, Boeing, etc.) response. 
While most respondents enjoyed these tours, they reported that they did not believe they were as valuable as other internship components. Also receiving significant responses were airline pass privileges (riding as a passenger, not to be confused with OMC privileges, which occur on the flight deck) and the intern project.

\section{Overall Evaluation}

At the end of the survey instrument respondents were asked to respond to one overall evaluative question each about the "short" internship, the "long" internship and the SIUC aviation curriculum.

Regarding the "short" internship, respondents were asked: "what impact has the 'short' internship experience had in achieving your aviation career goals"? As listed in Table 9, the response options given for this question were: Great Impact, Significant, Some, Little, No Impact and N/A (not applicable). The "Hired by United" is, for good reason, quite positive in its evaluation of the "short" internship with $75 \%$ of those respondents saying that the "short" internship had either "Great Impact or Significant Impact" on achieving their career goals. This differs substantially from the "Not Hired" by United respondent group which reported $38.1 \%$ of the responses in the "Great Impact or Significant Impact" categories. Also, 23.8\% of the "Not Hired" respondents said that the "short" internship and "Little or No Impact," while none of the "Hired" respondents responded in these two categories.

Regarding the "long" internship, respondents were asked, "What impact has the "long" internship experience had in achieving your aviation career goals"? Again, respondents were given a Likert-type scale of six possible responses: Great impact, Significant, Some, Little, No Impact and N/A (not applicable). Again, as shown in Table 10, the "Hired" by United group of respondents was clear in their response: Nearly $92 \%$ said that the "long" internship had "Great Impact" on their career goal achievement. This compares to only $38.1 \%$ of the "Not Hired" group of respondents who answer "Great Impact". The two groups combined indicated 62.8\% "Great Impact". On the other end of the scale 5 of all respondents $(6.4 \%)$ indicated that the "long" internship had "No Impact" on their career goal achievement.

With regard to an overall evaluation of aviation department coursework at SIUC (see Table 11) respondents were asked to answer the following question using a Likert-type scale: "How well did the coursework in the aviation department at SIUC prepare you for your internship"? A total of $78.5 \%$ of the "Not Hired" by United group responded that the coursework prepared them "Very Well or Well" while only $72.2 \%$ of the "Hired" group responded in this manner.

Overall, a total of 4 respondents ( 3 in the "hired" group and 1 in the "Not Hired" group), or a total of $5.1 \%$ of the overall respondent group, answered "Not Much". There were no responses in the "Did Not" category.

A final structured question asked, "would you recommend a United Airlines internship to students seeking an aviation career?" A total of 75 respondents $(96.2 \%)$ said that they "Would Recommend" the internship while 2 said that they would not. One respondent did not respond to this particular question.

\section{CONCLUSIONS}

The following conclusions can be derived about the respondent's perceptions of curricular preparation for a major airline flight internship program; as well as their 
overall views about the internship program and its components:

1. The "Most Helpful/Very Helpful" $(\mathrm{MH} / \mathrm{VH})$ coursework in preparing intern candidates for the flight operations internship at United are (when looking only at the total number of respondents who reported taking a specific course and then calculating the percentage of those who took only that course and marked it as $\mathrm{MH} / \mathrm{VH}$ ):
A. AVM 373-Airline Management
B. Flight Training at SIUC
C. AMT 205-Cabin Environment and Jet Transport Systems
D. AMT 405-Flight Systems Management
E. AVM 385/ATS 332-Air Transport Labor Relations
F. AVM 402/ATS 421-Aviation Industry Career Development

Also, when asked "How well did the coursework in the aviation department at SIUC prepare you for your internship," a total of $75.7 \%$ of survey respondents indicated "Very Well" or "Well" with another $17.9 \%$ responding "Moderately".

2. When asked to evaluate the "short" internship, six "short" internship components were rated as most valuable/very valuable by a majority of all respondents:

A. Experiencing the airline work environment;

B. Interaction with United personnel;

C. Interview for the "Long" internship;

D. Presentation by United Personnel;

E. Short Internship Overall Experience; and,

F. Simulator time.
When the respondents were asked, "What impact has the "short" internship experience had in achieving your aviation career goals", 55.1\% of all respondents said that it had had either "Great Impact or Significant Impact" on achieving their career goals. This percentage went up to $75.0 \%$ for the subset of all respondents who were hired by United.

3. When asked how valuable the "long" internship had been in achieving career goals, $80.7 \%$ of all respondents reported that it has had "Great Impact or Significant Impact”. This percentage went up to $91.7 \%$ for the "Hired by United" subset of respondents. When asked to evaluate components of the "long" internship, the following five items were ranked "Most Valuable" or "Very Valuable" by $80 \%$ or more of all respondents:

A. Your Internship Experience;

B. Observer Member of Crew (OMC) Privileges;

C. "Long" Internship Overall Experiences;

D. Interaction with United Personnel; and,

E. Your Assigned Work Location with United.

4. In some areas of the survey there were significant differences in the responses between the "hired by United" group of respondents and the "not hired by United" group of respondents. For example, in rating the value of the short internship, $75 \%$ of the "hired" group reported it as being of "great" or "significant" impact while only $38.1 \%$ of the "not hired" group responded in this manner. Similarly, $91.7 \%$ of the "hired" group said that the long-internship had "great impact" on their career goal 
achievement; only $38.1 \%$ of the "not hired" group reported in this way. A positive rating of the United Airlines internship program appears to be encouraged among those participants who have been hired by United.

5. When asked, "Would you recommend a United Airlines internship to students seeking an aviation career," $96.2 \%$ of respondents said that they "Would Recommend" the internship.

\section{RECOMMENDATIONS}

Research for this paper did not discover any comprehensive study on the success of an airline's flight operation internship program or curricula used in preparing students for such internships. One recommendation to airlines which conduct these types of internship programs is to establish a follow up mechanism to determine to what degree these programs are successful in meeting the goals of both internship participants; the airline and the students. A second recommendation would be to include curricular preparation questions in such a follow-up study to establish the correlation between curricular preparation and success in the internship program. The final recommendation is that United Airlines, having been in the flight operations internship business for over ten years, follow up with all of its flight operations interns from each of the participating universities. Such research would provide invaluable insight to the effect of various aviation-related curriculums, from a variety of institutions, on the success of flight operations internship programs, specifically for United Airlines. 


\section{REFERENCES}

Bradley, P. (1997, September). Is the pilot shortage coming? Business and Commercial Aviation.

Kiteley, G. (1997, November 11). Auburn, AL: University Aviation Association.

McMillan, J. H. \& Schumacher, S. (1989). Research in Education, A Conceptual Introduction $\left(2^{\text {nd }}\right.$ ed.). New York: Harper-Collins.

NewMyer, D. A., Ruiz, J. R. \& Worrells, D. S. (1998). A pioneering university-airline flight internship program: A follow-up study of intern participants. The Journal of Aviation/Aerospace Education and Research, 8, 23-33.

NewMyer, D. A., Ruiz, J. R. (1997, September). Airline flight operations intern programs. Presentation to the Air Transportation Association Operations and Safety Forum, Hilton Head, SC.

NewMyer, D. A., Ruiz, J. R. (1997, September). Airline flight intern programs and major universities: A follow-up study of graduates. Presentation to the Air Transportation Association Operations and Safety Forum, Hilton Head, SC.

NewMyer, D. A. (1991, October). Status report: An airline-university cooperative pilot career program. College Aviation Review, 2(1), 15.

Phillips, W. (1996, November). Internships \& co-ops: Collegiate programs that can make your aviation career take off. Flight Training.

Schukert, M. A. (1993, May). Aviation Career Waypoints. Murfreesboro, TN: Middle Tennessee State University Aerospace Department.

Self, B. (1996, September 25). Southwest Airlines Internship Program Guidelines. Dallas, TX: Southwest Airlines.

Spencer, K. (1988, July 26). UAL Working Relationships with Aviation Colleges. Denver, CO: United Airlines.

Turney, M. A. (1997, September 22). Starting an internship program. Presentation to the Air Transport Association Operations and Safety Forum, Hilton Head, SC. 


\section{APPENDIX}

Descriptions of SIUC Aviation Management courses cited in this study (SIUC Undergraduate Catalog, 1997):

ATS 364/Work Center Management. A study of the problems of managing a small working unit (division, department, work center, section, etc.) within a larger unit (agency, company, regional office, etc.) Included items will be work center goals identification, staffing needs, monitoring of work process reporting, work center communications, and interpersonal relations within the work center. (p. 105)

ATS 416/Applications of Technical Information. This course is designed to increase student competence in analyzing and utilizing the various types of technical information encountered by managers in technical fields. (p.

ATS 383/Data Interpretation. A course designed for students beginning their major program of study to examine data use in their respective professions. Emphasis will be placed upon an understanding of the basic principles and techniques involved with analysis, synthesis, and utilization of data. (p. 105)

AMT 205/ Cabin Environment and Jet Transport Systems. Students will understand the atmospheric variables at different altitudes and the basic equipment required to cope with malfunction in the cabin pressurization and air-conditioning systems. Using the available information, jet transport aircraft and simulated training panels, they will understand the operation of and be able to identify the components of flight control systems, landing gear, fuel, anti-icing, and fire detection systems. They will be able to compare and analyze aircraft systems of current jet transport aircraft and to diagnose and resolve malfunction problems. They will have knowledge of procedures for aircraft ground handling, APU operation, and system servicing. (p. 156)

AMT 405/Flight Management Systems. Using industry type computer instruction and flight simulation trainers, the course will develop the knowledge for operation and management of autopilots, auto throttles, inertial reference systems, electronic instrument systems, and flight management computers on advanced technology type aircraft, such as the Boeing 737-400, 747400, Douglas MD-81 and MD-11. (p. 157)

\section{AVM 319/Aviation Occupational} Internships. Each students will be assigned to a departmentally approved work site engaged in activities related to the student's academic program and career objectives. The student will be assigned to an unpaid internship position and will perform duties and services in an instructional setting as previously arranged with the sponsoring work site supervisor. (p. 159)

\section{AVM 360/The Air Traffic Control System, Procedures and Rules. This course provides instruction in basic air traffic control procedures and phraseology used by personnel providing air traffic control services. Students will become familiar with Federal Aviation Administration handbook and federal aviation regulations that pertain to the operational responsibilities of an air traffic controller. (p. 159)}

AVM 370/Airport Planning. To acquaint the student with the basic concepts of airport planning and construction, as well as an 
investigation of various regulatory agencies in the industry and their functions. (p. 159)

AVM 377/Aviation Industry Regulations. A study of various regulatory agencies of the industry and their functions. (p. 159)

AVM 372/Airport Management. A study of the operation of an airport devoted to the phases of lighting, fuel systems, field marking, field buildings, hangars, and surrounding community. (p. 159)

AVM 373/Airline Management. A study of the administrative aspects of airline operation and management including a detailed study of airline organizational structure. (p. 159)

AVM 374/General Aviation Operations. A study of general aviation operations including fixed base operations (fuel, sales, flight training, charter, etc.), corporate aviation (business aviation, corporate flight departments, executive air fleets, etc.) and the general aviation aircraft manufacturing industry. (p. 159)

AVM 375/Legal Aspects of Aviation. The student will develop an awareness of air transportation. The course will emphasize basic law as it relates to contracts, personnel, liabilities, and legal authority of governmental units and agencies. (p. 159)

AVM 376/Aviation Maintenance Management. To familiarize the student with the functions and responsibilities of the aviation maintenance manager. Maintenance management at the fixed based operator, commuter/regional airline, and national carrier levels will be studied. (p. 159)

AVM 377/Aviation Safety Management. This course will survey the various aspects of aviation flight and ground safety management. Weather, air traffic control, mechanical and human factors in aviation safety management will be reviewed. ( $p$. 159)

AVM 385/Air Transport Labor Relations. Students will gain a general understanding of the economic situation of which labormanagement problems represent a subset. They will develop a perspective on the evolution of labor relations in the United States economy and on how the interaction of labor and management differs throughout the world. The collective bargaining section introduces the student to the techniques of bargaining used by labor and management in their ongoing interactions. (p. 159)

AVM 386/Fiscal Aspects of Aviation Management. An introduction to the fiscal problems encountered in the administration of aviation facilities and airline operations. (p. 159)

AVM 402/Aviation Industry Career Development. Introduces students to the various elements involved in obtaining a position in their chosen career field. Topics included are: personal inventories, placement services, employment agencies, interviewing techniques, resumes, letters of application, references, and employment tests. Each student will develop a portfolio including personal and professional information related to individual career goals. (p. 160)

AVM 460/National Airspace System. This course provides instruction on the national airspace system, its purpose and major components. It defines the Federal Aviation Administration's role in the operation, maintenance and planning of the national airspace system. (p.160) 


\section{Table 1}

Courses Taken in the Aviation Major

Course Title $\quad(\underline{\mathrm{n}}=78) \quad$ Number Taking $\quad \%$

\begin{tabular}{lll}
\hline 1. Flight Training at SIUC & 73 & 93.6 \\
2. AVM 371-Aviation Industry Regulation & 70 & 89.7 \\
3. AVM 373-Airline Management & 67 & 85.9 \\
4. AVM 385/ATS 332-Air Transport & 62 & 79.5 \\
$\quad$ Labor Relations & 61 & 78.2 \\
5. AVM 370-Airport Planning & 60 & 76.9 \\
6. AVM 372-Airport Management & 57 & 73.1 \\
7. ATS 364-Work Center Management & 56 & 71.8 \\
8. AVM 377-Aviation Safety Management & 55 & 70.5 \\
9. AVM 360-Air Traffic Control & 54 & 69.0 \\
10. ATS 416-Applications of & & 60.3 \\
Technical Information & 47 & \\
11. AVM 386-Fiscal Aspects of & & 43.6 \\
$\quad$ Aviation Management & 34 & \\
12. AVM 402/ATS 421- & & 31.0 \\
Aviation Industry Career Devel. & 32 & \\
13. ATS 383-Data Interpretation & 28 & 29.5 \\
14. AVM 460-National Airspace System & & \\
15. AMT 205-Cabin Environment & 23 & 21.8 \\
$\quad$ and Jet Transport Systems & 17 &
\end{tabular}

Note. Courses are listed ordinally by the total number of respondents taking each course. See Appendix for course descriptions. 
Table 2

Combined Numbers of "Most Helpful/Very Helpful" and "Least Helpful/Not Very Helpful” Responses by Course

\begin{tabular}{lrrrrr}
\hline \multicolumn{1}{c}{ Course Title $(\underline{\mathrm{n}}=78)$} & Total & MH/VH $\%$ & LH/NVH & $\%$ \\
\hline Flight Training & 73 & 59 & 80.8 & 2 & 2.7 \\
AVM 371 & 70 & 25 & 35.7 & 8 & 11.4 \\
AVM 373 & 67 & 55 & 82.1 & 3 & 4.5 \\
AVM 385/ATS 332* & 62 & 40 & 64.5 & 3 & 4.8 \\
AVM 370 & 61 & 9 & 14.8 & 24 & 39.3 \\
AVM 372 & 60 & 15 & 25.0 & 19 & 31.7 \\
ATS 364 & 57 & 8 & 14.0 & 19 & 33.3 \\
AVM 377 & 56 & 20 & 35.7 & 7 & 12.5 \\
AVM 360 & 55 & 9 & 34.5 & 13 & 23.6 \\
ATS 416 & 54 & 1 & 20.4 & 12 & 22.2 \\
AVM 386 & 47 & 20 & 42.6 & 10 & 21.3 \\
AVM 402/ATS 421* & 34 & 20 & 58.8 & 2 & 5.9 \\
ATS 383 & 32 & 3 & 9.4 & 19 & 59.4 \\
AVM 460 & 28 & 7 & 25.0 & 5 & 17.9 \\
AMT 205 & 23 & 15 & 65.2 & 4 & 17.4 \\
AMT 405 & 17 & 11 & 64.7 & 1 & 5.9 \\
& & & & & \\
\hline
\end{tabular}

Note. Course Titles are listed ordinally by the total number of respondents taking each course. $\mathrm{MH} / \mathrm{VH}=$ Most Helpful/Very Helpful (combined responses) and LH/NVH = Least Helpful/Not Very Helpful (combined responses). *ATS 421 converted to AVM 402 in 1996; ATS 332 converted to AVM 385 in 1996. See Appendix for course descriptions. 
Table 3

Top 5 Courses Ranked as "Most Helpful" (MH) and "Very Helpful" (VH) by Respondent Group

\begin{tabular}{lcccc}
\hline All Respondents $(\mathrm{n}=78)$ & & & & Total \\
\hline Course Title & MH & VH & & \\
\hline Flight Training at SIUC & 32 & 27 & $=$ & 59 \\
Airline Management & 28 & 27 & $=$ & 55 \\
Air Transport Labor Relations & 12 & 28 & $=$ & 40 \\
Aviation Industry Regulations & 4 & 21 & $=$ & 25 \\
Aviation Safety Management* & 5 & 15 & $=$ & 20 \\
Fiscal Aspects of Aviation & 6 & 14 & $=$ & 20 \\
$\quad$ Management* & 13 & 7 & $=$ & 20 \\
Aviation Industry Career & & & & \\
$\quad$ Development* & & & & \\
\end{tabular}

Hired by United $(\mathrm{n}=36)$

$\begin{array}{lllll}\text { Flight Training at SIUC } & 14 & 15 & = & 29\end{array}$

Air Transport Labor Relations* $\quad 8 \quad 15=23$

AVM 373 "Airline Management* $12 \quad 11=23$

$\begin{array}{lllll}\text { Aviation Industry Regulations } & 4 & 12 & =\end{array}$

$\begin{array}{llll}\text { Aviation Safety Management } & 5 & 7 & =\end{array}$

Not Hired by United $(\mathrm{n}=42)$

$\begin{array}{lrrrr}\text { Airline Management } & 16 & 16 & = & 32 \\ \text { Flight Training at S IUC } & 18 & 12 & = & 30 \\ \text { Air Transport Labor Relations } & 4 & 13 & = & 17 \\ \text { Fiscal Aspects of Aviation } & 4 & 9 & = & 13 \\ \quad \text { Management } & & & & 12 \\ \quad \begin{array}{l}\text { Aviation Industry Career } \\ \quad \text { Development }\end{array} & 7 & 5 & \end{array}$

Note. ${ }^{*}$ Indicates a tie in ranking. See Appendix for course descriptions. 


\section{Table 4}

Bottom 5 Courses Ranked as "Least Helpful" (LH) and "Not Very Helpful" (NVH) Respondent Group

\begin{tabular}{|c|c|c|c|c|}
\hline \multicolumn{5}{|l|}{ All Respondents $(\mathrm{n}=78)$} \\
\hline Course Title & LH & $\mathrm{NVH}$ & & Total \\
\hline$\overline{\text { Airport Planning }}$ & 8 & 16 & $=$ & 24 \\
\hline Airport Management* & 5 & 14 & $=$ & 19 \\
\hline Data Interpretation* & 7 & 12 & $=$ & 19 \\
\hline Work Center Management* & 8 & 11 & $=$ & 19 \\
\hline Air Traffic Control & 5 & 8 & $=$ & 13 \\
\hline \multicolumn{5}{|l|}{ Hired by United $(\mathrm{n}=36)$} \\
\hline Airport Planning* & 3 & 10 & $=$ & 13 \\
\hline Airport Management* & 3 & 10 & $=$ & 13 \\
\hline Air Traffic Control & 2 & 5 & $=$ & 7 \\
\hline $\begin{array}{l}\text { Fiscal Aspects of Aviation } \\
\text { Management* }\end{array}$ & 1 & 6 & $=$ & 7 \\
\hline Data Interpretation* & 0 & 4 & $=$ & 4 \\
\hline Work Center Management* & 4 & 0 & $=$ & 4 \\
\hline \multicolumn{5}{|l|}{ Not Hired by United $(n=42)$} \\
\hline Data Interpretation* & 7 & 8 & $=$ & 15 \\
\hline Work Center Management* & 4 & 11 & $=$ & 15 \\
\hline Airport Planning & 5 & 6 & $=$ & 11 \\
\hline $\begin{array}{l}\text { Applications of Technical } \\
\text { Information }\end{array}$ & 4 & 6 & $=$ & 10 \\
\hline Air Traffic Control* & 3 & 3 & $=$ & 6 \\
\hline Airport Management* & 2 & 4 & $=$ & 6 \\
\hline
\end{tabular}

Note. *Indicates a tie in ranking. See Appendix for course descriptions. 


\section{Table 5}

Evaluation of "Short" Internship Experience

\begin{tabular}{llr}
\hline Overall Respondent Group $(\mathrm{n}=78)$ & & \\
Course Title & MV/VV & NV/SV \\
& & 0 \\
\hline Experiencing the airline work & 61 & \\
$\quad$ environment & 59 & 3 \\
Interaction with United personnel & 52 & 3 \\
Interview for the "long internship" & 50 & 4 \\
Presentation by United personnel & 42 & 9 \\
"Short internship" overall experience* & 42 & 12 \\
Simulator Time* & 36 & 7 \\
Group project with other interns & 34 & 5 \\
Tours of "TK" & 31 & 4 \\
Tours of EXO/WHQ & 28 & 14 \\
767 (or other) Ground School & 24 & \\
Tours of DEN/DIA & & \\
& & \\
\hline
\end{tabular}

\section{Hired by United $(\mathrm{n}=36)$}

Interaction with United personnel 26

Experiencing the airline work environment* 25

Presentation by United personnel* 25

Interview for the "long internship" 24

"Short internship" overall experience 23

Simulator Time 19

767 (or other) Ground School

7

Group Project with other interns

Tours of TK

$16 \quad 3$

Tours of EXO/WHQ

$14 \quad 5$

$13-5$

Tours of DEN/DIA

$9-6$

Not Hired by United $(\mathrm{n}=42)$

Experiencing the airline work environment Interaction with United personnel

Interview for the "long internship"

Presentation by United personnel

Simulator Time

Group project with other interns

Tours of TK

Tours of EXO/WHQ*

"Short internship" overall experience*

Tours of DEN/DIA

3
5
5
2
6


Note. Items listed in order of their "Most Valuable/Very Valuable"

responses. *Indicates

a tie in ranking (MV/VV). MV/VV = Most Valuable/Very Valuable. NV/SV

$=$ Not Valuable/Somewhat Value.

Table 6

Evaluation of "Long" Internship Experience

Overall Respondent Group ( $\mathrm{n}=78$ )

Course Title

$\mathrm{MV} / \mathrm{VV}$

$\mathrm{NV} / \mathrm{SV}$

\begin{tabular}{lll}
\hline Your Internship Experience & 69 & 4 \\
Observer Member of Crew Privileges* & 68 & 2 \\
"Long” Internship Overall Experience* & 68 & 2 \\
Interaction with United Personnel & 67 & 2
\end{tabular}

(other than your supervisor)

Your assigned work location at United $\quad 63 \quad 5$

$\begin{array}{llr}\text { Your internship supervisor } & 54 & 10\end{array}$

Simulator Time 47

Interaction with other Interns* 44

Tours of MOC at SFO* 44

Tours of the Boeing Plant 42

Specific Intern Project $\quad 40$

Airline Pass Privileges

9

Visits to TK (if assigned elsewhere)

Hired by United $(\mathrm{n}=36)$

Your internship experience $\quad 31$

Interaction with United Personnel*

(other than supervisor)

Long internship overall experience* 29

Your assigned work location at United* 28

Observer Member of Crew Privileges* 28

Your internship supervisor $\quad 27$

Simulator time

Tours of MOC at SFO

9. Tours of the Boeing Plant 19

Interaction with other interns* 18

Specific intern project* 18

Airline Pass Privileges

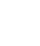

6


Not Hired by United $(\mathrm{n}=42)$

Observer Member of Crew Privileges $\quad 40$

“Long” Internship overall experience $\quad 39$

Interaction with United Personnel* 38

Your internship experience* 38

Your assigned work location at United 35

Your internship supervisor $\quad 27$

Simulator Time* 26

Interaction with other interns* 26

Tours of MOC at SFO 24

Tours of Boeing Plant 23

Specific intern project 22

Airline Pass Privileges

18

Visits to TK (if assigned elsewhere)

1

10

Note. Items listed in order of their combined "Most Valuable/Very Valuable" responses.

*Indicates a tie in ranking.

\section{Table 7}

Respondent Ranking of Most Valuable “Long” Internship Components

Combined First, Second and Third Responses

\begin{tabular}{ll}
\hline Interaction with United Personnel & 46 \\
OMC Privileges & 40 \\
Overall Experience & 23 \\
Assigned Work Location* & 23 \\
Simulator Time/Experience* & 23 \\
Relationship with Internship Supervisor & 18 \\
Your Intern Experience & 17
\end{tabular}

Note: All other components received less than ten responses. *Indicates a tie in ranking 
Table 8

Respondent Ranking of Least Valuable "Long” Internship Components

Combined First, Second and Third Responses

\begin{tabular}{ll}
\hline Tours (Boeing, MOC, etc.) & 37
\end{tabular}

Airline Pass Privileges $\quad 28$

Intern Project 21

Interaction with other Interns 16

Simulator Time/Experience 13

Visits to TK 11

Relationship with Supervisor $\quad 10$

Note: All other components received less than 10 responses.

Table 9

Responses to the Question: "What impact has the "short internship experience had in achieving your aviation career goals?"

\begin{tabular}{|c|c|c|c|c|c|c|}
\hline \multicolumn{3}{|c|}{ Not Hired $(\underline{n}=42)$} & \multicolumn{2}{|c|}{ Hired $(\underline{\mathrm{n}}=36)$} & \multicolumn{2}{|c|}{ Totals $(\underline{\mathrm{n}}=78)$} \\
\hline Response & Nun & er $/ \%$ & $\overline{\mathrm{Nur}}$ & er / \% & $\mathrm{Nu}$ & er $/ \%$ \\
\hline Great Impact & 5 & $/ 11.9$ & 15 & $/ 41.7$ & 20 & $/ 25.6$ \\
\hline Significant & 11 & $/ 26.2$ & 12 & $/ 33.3$ & 23 & $/ 29.5$ \\
\hline Some & 10 & $/ 23.8$ & 2 & / 5.6 & 12 & $/ 15.4$ \\
\hline Little & 7 & $/ 16.7$ & 0 & / 0.0 & 7 & / 9.0 \\
\hline No Impact & 3 & / 7.1 & 0 & $/ 0.0$ & 3 & / 3.8 \\
\hline N/A & 5 & $/ 11.9$ & 7 & $/ 19.4$ & 12 & $/ 15.4$ \\
\hline No Response & 1 & / 2.4 & 0 & $/ 0.0$ & 1 & / 1.3 \\
\hline Total & 42 & $/ 100 \%$ & 36 & $/ 100 \%$ & 78 & $/ 100 \%$ \\
\hline
\end{tabular}




\section{Table 10}

Responses to the Question: "What Impact has the "long" internship had in achieving your aviation career goals"?

\begin{tabular}{|c|c|c|c|c|c|c|}
\hline \multicolumn{3}{|c|}{ Not Hired $(\underline{n}=42)$} & \multicolumn{2}{|c|}{ Hired $(\underline{n}=36)$} & \multicolumn{2}{|c|}{ Totals $(\underline{\mathrm{n}}=78)$} \\
\hline Response & $\mathrm{Nul}$ & er / \% & $\mathrm{Nu}$ & er $/ \%$ & $\mathrm{Nu}$ & oer / \% \\
\hline Great Impact & 16 & $/ 38.1$ & 33 & $/ 91.7$ & 49 & $/ 62.8$ \\
\hline Significant & 14 & $/ 33.3$ & 0 & / 0.0 & 14 & $/ 17.9$ \\
\hline Some & 8 & /19.1 & 0 & / 0.0 & 8 & $/ 10.3$ \\
\hline Little & 0 & / 0.0 & 0 & $/ 0.0$ & 0 & / 0.0 \\
\hline No Impact & 3 & / 7.1 & 2 & / 5.5 & 5 & / 6.4 \\
\hline N/A & 0 & / 0.0 & 1 & / 2.8 & 1 & / 1.3 \\
\hline No Response & 1 & / 2.4 & 0 & / 0.0 & 1 & / 1.3 \\
\hline Totals & 42 & $/ 100 \%$ & 36 & $/ 100 \%$ & $\overline{78}$ & $/ 100 \%$ \\
\hline
\end{tabular}

\section{Table 11}

Responses to the Question: "How well did the coursework in the aviation department at SIUC prepare you for your internship?"

\begin{tabular}{|c|c|c|c|c|c|c|}
\hline \multicolumn{3}{|c|}{ Not Hired $(\underline{n}=42)$} & \multicolumn{2}{|c|}{ Hired $(\underline{\mathrm{n}}=36)$} & \multicolumn{2}{|c|}{ Totals $(\underline{\mathrm{n}}=78)$} \\
\hline Response & $\mathrm{Nu}$ & per / \% & $\mathrm{Nu}$ & er / \% & $\mathrm{Nu}$ & er $/ \%$ \\
\hline Very Well & 10 & $/ 23.8$ & 9 & $/ 25.0$ & 19 & $/ 24.4$ \\
\hline Well & 23 & 154.7 & 17 & $/ 47.2$ & 40 & $/ 51.3$ \\
\hline Moderately & 7 & $/ 16.7$ & 7 & $/ 19.5$ & 14 & $/ 17.9$ \\
\hline Not Much & 1 & / 2.4 & 3 & / 8.3 & 4 & / 5.1 \\
\hline Did Not & 0 & / 0.0 & 0 & / 0.0 & 0 & / 0.0 \\
\hline $\mathrm{N} / \mathrm{A}$ & 0 & / 0.0 & 0 & / 0.0 & 0 & / 0.0 \\
\hline No Response & 1 & / 2.4 & 0 & / 0.0 & 1 & / 1.3 \\
\hline Totals & 42 & $/ 100 \%$ & 36 & $/ 100 \%$ & $\overline{78}$ & $/ 100 \%$ \\
\hline
\end{tabular}

